\title{
Soldagem em Operação de Dutos de Alta Resistência e Baixa Espessura com Ênfase nas Trincas a Frio
}

\author{
(In-service Welding of Pipelines in High Strength Low Thickness with Emphasis on Cold Cracks)
}

\author{
Aldo Santos Pereira ${ }^{(1)}$, Augusto J. A. Buschinelli (2), Carlos E. Niño ${ }^{(2)}$, Norton Zanette Kejelin ${ }^{2,3}$ \\ ${ }^{1}$ UTFPR, DAMEC, Curitiba, Paraná,Brasil, santos@utfpredu.br \\ ${ }^{2} U F S C$, EMC/LABSOLDA, Florianópolis, Santa Catarina, Brasil (buschi@emc.ufsc.br) \\ ${ }^{3}$ Faculdade Satc, Departamento de Eng ${ }^{a}$ Mecânica, Criciúma, Santa Catarina, Brasil
}

\begin{abstract}
Resumo
O objetivo deste trabalho foi avaliar a ocorrência de trincas a frio quando da soldagem de dutos em operação. Foram executados dois conjuntos de experimentos: o primeiro denominado de experimento " $F$ ", em que foi variada a folga entre a calha e o tubo, e utilizados metal de base e de adição de alto carbono equivalente; o segundo denominado de experimento " $R$ ", em que foi imposta alta restrição à junta soldada e, promovido o resfriamento rápido mediante fluxo de água no interior do tubo. Foram feitas as soldagens com os seguintes processos e materiais: processo eletrodo revestido (SMAW), tubo e calha em aço ASTM A 335 P5, metal de adição AWS E 8018-B8 (experimento “F”). Processos MIG/MAG pulsado (GMAW-P) e arame tubular auto-protegido (FCAW-S), tubo e calha em aço API 5L X70, metais de adição AWS ER 80S-G e AWS E 71T-11, respectivamente (experimento " $R$ "). Para detectar as trincas a frio foram realizados exame visual e a inspeção com líquidos penetrantes. Adicionalmente as soldas foram avaliadas por macrografia e medição de dureza. Não foram detectadas trincas, apesar da utilização de metais de base e de adição com alto carbono equivalente e da junta com alta restrição, com o objetivo de aumentar as tensões. Admite-se que não houve fissuração devido ao uso de processos el consumiveis com baixo teor de hidrogênio.
\end{abstract}

Palavras-chave: Trinca a frio. Soldagem em operação. Soldagem de calha sobre tubo.

Abstract: The aim of this study was to evaluate the occurence of cold cracks associated with in-service welding of pipelines. Two sets of experiments were performed: the first of them was called experiment " $F$ ", where the gap between sleeve and pipe was varied and base and weld metal of high carbon equivalent were used, the second set of experiment was denominated " $R$ ", when higher restriction was imposed to the welded joint, which was simultaneously more rapid cooled by water flow within the pipe. The welds were made with the following procedures and materials: shielded metal arc welding (SMAW) of tube and pipeline steel ASTM A 335 P5, using AWS E 8018-B8 as weld metal (experiment F). Pulsed MIG / MAG (GMAW-P) and self-shielded cored wire (FCAW-S) welding of tube and pipeline steel API 5 L X70, by using respectively AWS ER 80S-G and AWS E 71T-11 filler metals (experiment " $R$ "). To detect cold cracks visual and penetrant liquid inspection were performed. Additionally the welds were evaluated by macrography and microhardness measurements. No cracks were detected, despite the use of basic and filler metals of high carbon equivalent and the higher restraint and therefore more stressed joint. It is assumed that the integrity of the welded joints was due to the use of processes and / consumables with low hydrogen content.

Key-words: Cold crack. Iin-service welding. Sleeve welding on pipe.

\section{Introdução}

Uma das técnicas comumente empregadas na modificação, reparo ou expansão de uma malha de dutos é a soldagem realizada com a tubulação em operação, que permite a intervenção sem interromper o escoamento do fluido. Reparos por soldagem e colocação de conexões para derivação (hot tape) em tubulação pressurizada em operação tem a vantagem de evitar paradas (troca de trechos) e perdas de receitas pelas empresas proprietárias de dutos. Além das evidentes vantagens econômicas, a soldagem nestas condições, ainda que em algumas

(Recebido em 05/03/2012; Texto final em 16/05/2012). situações exija redução na vazão e/ou pressão do fluido, tem positivos reflexos ambientais.

Nesse contexto é importante destacar o uso cada vez maior de aços de alta resistência na produção de tubos para condução de óleo e gás. A principal vantagem da utilização de dutos com graus elevados de resistência mecânica é a redução do custo total de material. Esta redução se baseia na premissa de que ao aumentar o limite de escoamento, a espessura de parede requerida para resistir às pressões internas (ou externas em caso de águas profundas) pode ser reduzida. Isso traz como vantagens adicionais a diminuição do peso e a facilidade na fabricação e montagem, além de requerer menor quantidade de metal de adição e outros consumíveis de soldagem, acarretando menores custos de mão de obra. Alternativamente, se grandes espessuras de parede forem mantidas, os dutos fabricados com estes aços 


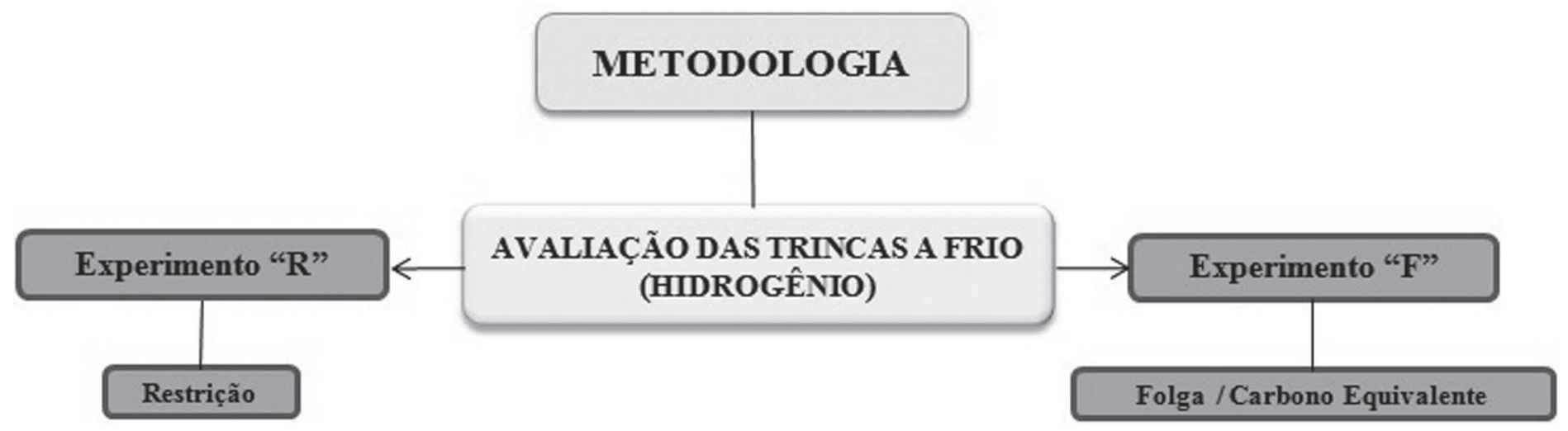

Figura 1. Fluxograma mostrando a metodologia adotada neste trabalho.

podem receber maiores pressões de trabalho, resultando em economia na instalação e operação em longas distâncias. A utilização de aços a partir dos graus API 5L X70 e X80 têm dominado o mercado mundial e a utilização de graus superiores é considerada uma tendência irreversível.

Entretanto novas exigências quanto à qualidade de tubos visam aumentar a segurança e a preservação do meio ambiente. No desenvolvimento de aços para dutos, além da resistência, deve-se atentar para a tenacidade, soldabilidade, resistência às trincas induzidas por hidrogênio, resistência à fadiga nas juntas soldadas e resistência à corrosão. Cada sistema de dutos deve apresentar bons níveis de tenacidade, com a preocupação da redução do risco de nucleação e propagação de trincas.

Uma situação especial a ser considerada, refere-se ao fato de que soldas executadas em dutos em operação sofrem resfriamento acelerado pelo escoamento do fluido e, portanto, poderão conter regiões de elevada dureza suscetíveis a trincas a frio induzidas pelo hidrogênio.

As trincas a frio em juntas soldadas de aços de alta resistência estão bem caracterizadas, bem documentadas, e os mecanismos de falha bem conhecidos. Extensivos esforços têm-se colocado para reconhecer e selecionar os parâmetros de soldagem e os materiais que são promotores das trincas a frio. Contudo, estes esforços de engenharia não têm eliminado totalmente a ocorrência de tais falhas $[1,2]$.

As trincas a frio (induzidas pelo hidrogênio) são as descontinuidades mais criticas com respeito à integridade do duto e somente ocorrerão sob determinadas condições especificas. Ocorre normalmente na zona afetada pelo calor (ZAC) e em alguns casos no metal de solda (MS) depositado. As condições necessárias para a ocorrência da trinca a frio são: Microestrutura suscetível (normalmente a martensita), presença do hidrogênio na solda, tensões trativas (aplicadas e/ou residual) e a baixa temperatura $\left(<150^{\circ} \mathrm{C}\right)[2,3]$.

Outro fator de interesse em relação a integridade no reparo de dutos é a ocorrência descontinuidades induzida pelo soldador tais como: inclusões de escórias, falta de fusão/penetração e mordeduras [2].

Em função da alta velocidade de resfriamento obtida durante a soldagem de reparo de dutos em operação pela presença do fluido interno, pode facilmente proporcionar o surgimento da trinca a frio. $\mathrm{O}$ aumento do aporte de calor ou a redução da velocidade de resfriamento conduz a redução da dureza e uma microestrutura mais adequada, nestas condições baixa a suscetibilidade da trinca a frio induzida pelo hidrogênio [4].

Este trabalho tem como objetivo definir critérios e métodos que permitam estabelecer condições de soldagem em operação de tubulações de pequena espessura, evitando o risco de trincas a frio induzida pelo hidrogênio em aços API 5L de maior resistência X70, ao executar soldas de filete (para instalação de calha sobre duto).

\section{Materiais e Métodos}

Foram executados dois conjuntos de experimentos distintos, denominados de "F" e "R" de acordo com o fluxograma da figura 1.

Experimento "F": em função da folga e do alto carbono equivalente. Antes da montagem da bancada de testes foram executadas soldagens nas condições mais críticas, objetivando o surgimento de trincas.

Nesta avaliação foram executadas duas soldas manuais com o processo eletrodo revestidos em condições distintas, a saber, junta $\mathrm{C}$ com pré-aquecimento de $180^{\circ} \mathrm{C}$ e ressecagem do eletrodo e junta $\mathrm{D}$ sem pré-aquecimento e sem ressecagem do eletrodo (figura 2). As variáveis de soldagem foram as mesmas para as duas juntas: passe único; corrente de 150A; tensão de 27 $\mathrm{V}$; velocidade de soldagem $18,0 \mathrm{~cm} / \mathrm{min}$. e energia de soldagem de $13,5 \mathrm{~kJ} / \mathrm{cm}$. Desta forma foram realizados os experimentos nas condições:

a) utilizado-se de materiais de alta resistência e com alto carbono equivalente (tabela 1 e 2);

b) aplicando-se a técnica de soldagem em calha com tubo, particularmente para o passe de raiz;

c) verificando-se a influência da folga (gap) maior que 5,0 mm (figura 3), como pode ocorrer ao instalar-se calha em dutos que apresente ovalização.

Experimento "R": em função da restrição imposta à junta soldada foram executadas soldagens com restrição, em tubos e calhas API 5L X70 nas seguintes condições (figura 4):

a) Processo GMAW com corrente pulsada, técnica empurrando (junta A e B), Im = 180A; $\quad \mathrm{Um}=25,3 \mathrm{~V}$; Vs $=25 \mathrm{~cm} / \mathrm{min}$.; $\mathrm{Es}=10,9 \mathrm{~kJ} / \mathrm{cm}$; com água na vazão de 801 e pressão de 2 bar.

b) Processo FCAW-S transferência goticular e tocha reta (junta 
A1 e B1), Im = 170 A; Um = 22,3 V; Vs $=25 \mathrm{~cm} / \mathrm{min}$; $\mathrm{Es}=9,1$ $\mathrm{kJ} / \mathrm{cm}$,; com água na vazão de 801 e pressão de 2 bar.

Após a execução da soldagem da junta de filete da calha com o tubo, foi realizado ensaio não destrutivo por líquido penetrante e posteriormente retiradas três seções para o mesmo filete de solda, nas quais foram feitas as análises macrográfica, de dureza e fotográfica.

\subsection{Materiais}

Foi executada a soldagem para avaliação da trinca a frio em função da folga entre a calha e tubo. Para isto, foi utilizado um metal de base de maior temperabilidade, tubo ASTM A-335 P5 no $\phi 5$ " e espessura de parede de $6,3 \mathrm{~mm}$, composição química de acordo com a tabela 1; metal de adição eletrodo AWS E 8018-B8 com $\phi 3,2 \mathrm{~mm}$ cuja composição química pode ser vista na tabela 2. Por outro lado, para a verificação da ocorrência da trinca a frio em função da restrição imposta à junta foi utilizado como metal de base o tubo API 5L X70 (tabela 3), e como metais de adição foram utilizados, para o processo de soldagem GMAW o arame eletrodo ER $80 \mathrm{~S}$ - G (tabela 4) e para o processo FCAW o eletrodo E 71T-11 (tabela 5).

Tabela 1. Composições químicas do tubo ASTM A 335 P5

\begin{tabular}{l|c|c}
\hline \hline Elemento & $(*) \%$ Em peso / Analisado & $\%$ Em peso/Norma \\
\hline \hline Carbono & 0,07 & máx. 0,15 \\
Manganês & 0,56 & $0,30-0,60$ \\
Silício & 0,26 & min. 0,50 \\
Fósforo & 0,010 & máx. 0,025 \\
Enxofre & 0,016 & máx. 0,025 \\
Cromo & 5,30 & $4,00-6,00$ \\
Molibdênio & 0,44 & $0,45-0,65$
\end{tabular}

(*) Espectrometria de emissão ótica $\mathrm{CE}_{\text {(IIW) }}=1,31$

Tabela 2. Composições químicas do eletrodo AWS E 8018 - B8

\begin{tabular}{l|cc}
\hline \hline Elemento & $(*) \%$ Em peso / Analisado & \% Em peso/Norma \\
\hline \hline Carbono & 0,073 & $0,05-0,10$ \\
Manganês & 0,505 & máx. 1,00 \\
Silício & 0,400 & máx. 0,90 \\
Fósforo/Enxo & 0,013 & máx. 0,03 \\
Cromo & 8,833 & $8,0-10,5$ \\
Molibdênio & 0,866 & $0,85-1,20$ \\
Níquel & 0,163 & máx. 0,40 \\
\hline
\end{tabular}

$(*)$ Valores obtidos no certificado da qualidade do fornecedor Böhler. $\mathrm{CE}_{\text {(II) }}=2,1$

Tabela 3. Composição química do tubo API 5L X70.

\begin{tabular}{l|c|c}
\hline \hline Elemento & \% Em peso & Norma \\
\hline \hline Carbono & máx. 0,24 & máx. 0,22 \\
Manganês & máx. 1,20 & máx. 1,65 \\
Fósforo & máx. 0,025 & máx. 0,025 \\
Enxofre & máx. 0,015 & máx. 0,015
\end{tabular}

(*) Valores obtidos no certificado da qualidade do fornecedor Böhler. $\mathrm{CE}_{(\mathrm{IIW})}=2,1$
Tabela 4 - Composição química do arame AWS ER 80S-G

\begin{tabular}{l|c|c}
\hline \hline Elemento & $(*) \%$ Em peso/Analisado & $\%$ Em peso/Norma \\
\hline \hline Carbono & 0,074 & \\
Manganês & 1,350 & \\
Silício & 0,750 & Não Especificada \\
Fósforo & 0,013 & \\
Enxofre & 0,012 & \\
Cromo & 0,028 & \\
Molibdênio & 0,470 & \\
\hline
\end{tabular}

$(*)$ Valores obtidos no certificado da qualidade do fornecedor KESTRA. $\mathrm{CE}_{\text {(IIW) }}=0,413$.

Tabela 5 - Composição química do eletrodo AWS E 71T-11

\begin{tabular}{l|cc}
\hline \hline Elemento & $(*) \%$ Em peso/Analisado & \% Em peso/Norma \\
\hline \hline Carbono & 0,230 & máx. 0,30 \\
Manganês & 0,360 & máx. 1,75 \\
Silício & 0,120 & máx. 0,60 \\
Fósforo & 0,006 & máx. 0,03 \\
Enxofre & 0,006 & máx. 0,03 \\
Cromo & 0,030 & máx. 0,20 \\
Alumínio & 1,720 & máx. 1,80 \\
Cobre & 0,030 & máx. 0,35 \\
\hline
\end{tabular}

\subsection{Preparação dos corpos de prova}

Nas figuras 2 e 3 apresentadas a seguir, referentes ao experimento "F", mostra-se como se procedeu para verificar a ocorrência de trinca a frio pelo efeito da tensão residual proveniente da folga entre a luva e tubo e alto carbono equivalente. Na figura 4 é mostrada a configuração da junta e como foi executada a soldagem.

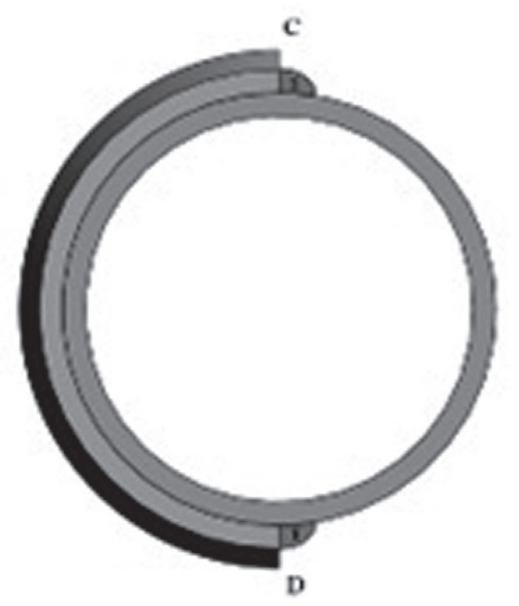

Figura 2. Desenho mostrando os locais das juntas C e D com a execução de um único passe e em condições distintas.

Com relação ao experimento " $\mathrm{R}$ " foi executada a soldagem com restrição para a verificação da possível ocorrência de trinca a frio decorrente do efeito da tensão residual. A figura 4 mostra em detalhes as restrições da junta. 


\section{Soldagem em Operação de Dutos de Alta Resistência e Baixa Espessura com Ênfase nas Trincas a Frio}

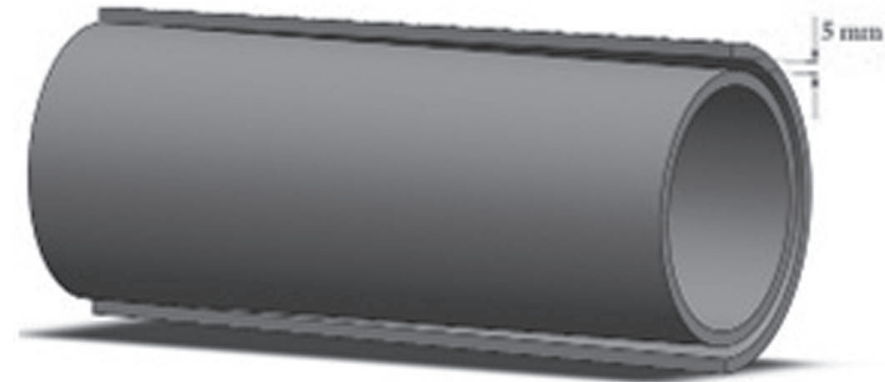

Figura 3. Desenho mostrado a folga de 0 a 5,0 $\mathrm{mm}$ entre a calha e o tubo.

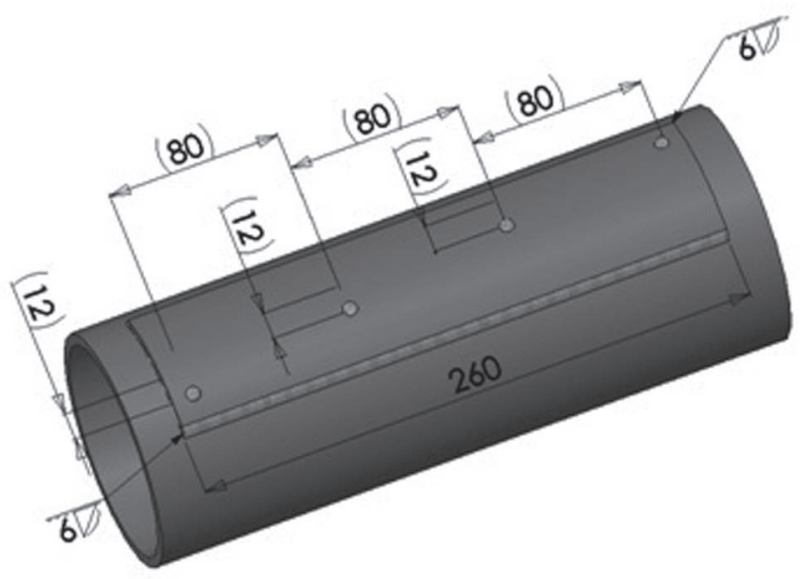

Figura 4. Desenho mostrando os detalhes da junta com restrição.

Foram levantados os perfis de dureza nas soldas de filete (junta de ângulo) para todas as soldas de calha e tubo conforme foto ilustrativa mostrada na figura 5. Para este levantamento foi utilizado um micro durômetro da marca SHIMADSU modelo HMV - 2000, os valores de dureza foram medidos na escala Vickers com carga aplicada de 300 gramas e tempo de aplicação de 15 segundos, sendo que a distância entre os pontos medidos foi de $200 \mu \mathrm{m}$. As medições de micro dureza Vickers foram efetuadas de acordo com a norma ASTM E 384 - 73.

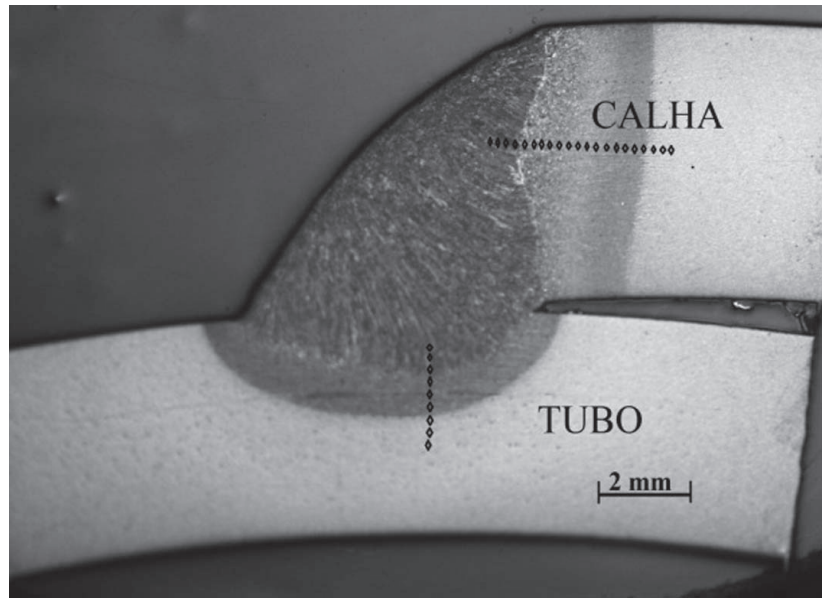

Figura 5 Foto ilustrativa mostrando os locais das medições de micro dureza.

\section{Resultados e Discussão}

\subsection{Efeito da folga entre a calha e tubo e do alto carbono equivalente.}

Os resultados da soldagem mostraram que em condições distintas (experimento "F"), para avaliação da ocorrência de trincas a frio, em diversas situações (com pré-aquecimento ou não, com ou sem ressecagem dos consumíveis e diferentes energias de soldagem) não foi observado o surgimento de trincas. Observa-se através da figura 5 o filete de soldagem denominado como junta $\mathrm{C}$, que foi usado tanto para calha como para o tubo de material ASTM A 335 Grau P5 (tabela 1). Foi soldado com o processo eletrodo revestido, o metal de adição escolhido foi de baixo hidrogênio AWS E 8018 - B8 (tabela 2), ambos com altíssimo carbono equivalente.

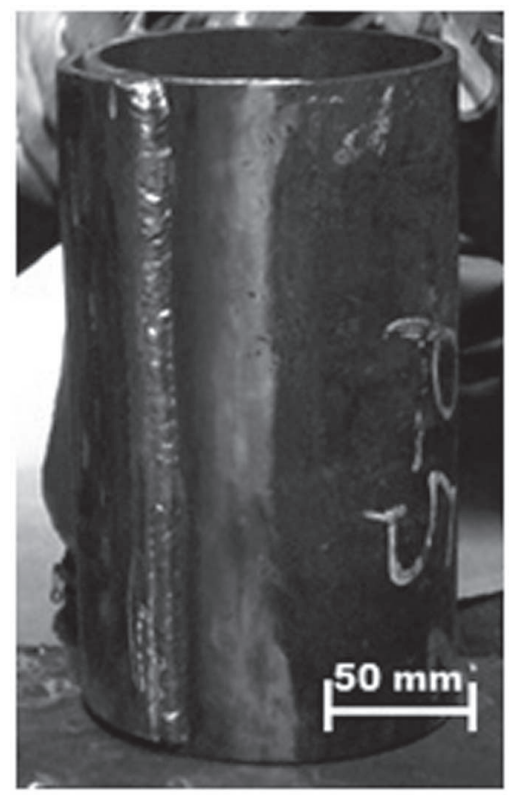

Figura 5. Foto mostrando a junta de filete soldada com eletrodo revestido na soldagem da calha/tubo no metal de base ASTM A 335 Grau P5 e metal de solda E 8018 - B8.

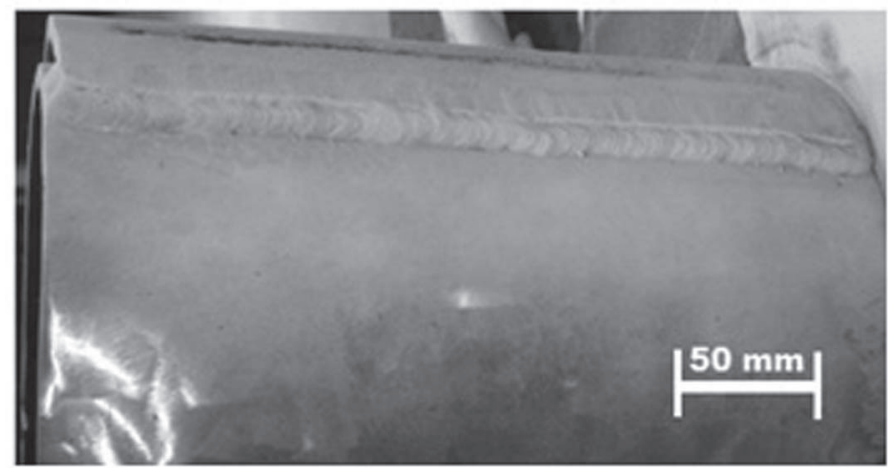

Figura 6. Foto do ensaio com liquido penetrante para a detecção de trinca superficial na soldagem da calha/tubo no metal de base ASTM A 335 Grau P5 e metal de solda E 8018 B8. 


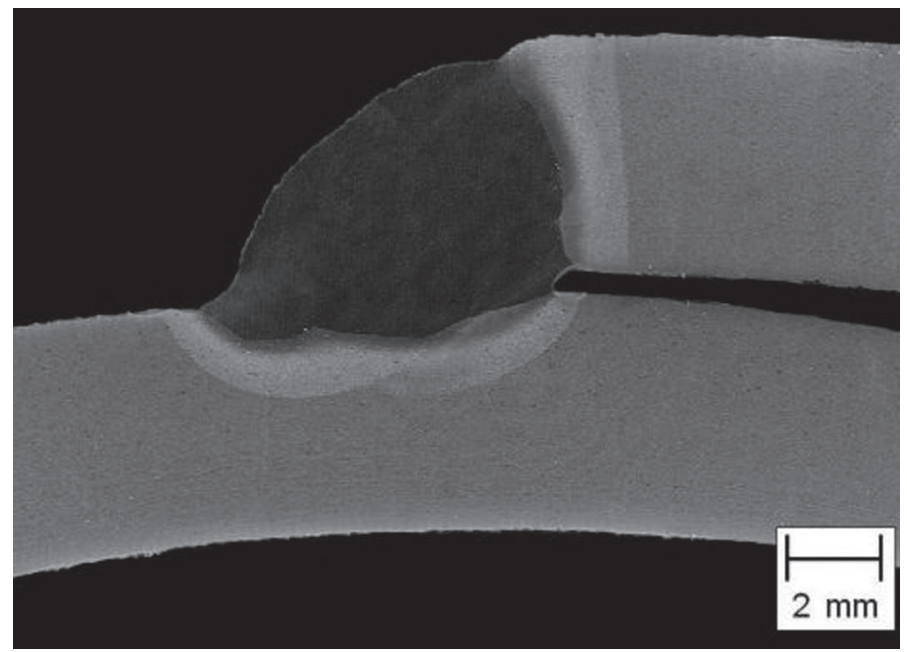

C1

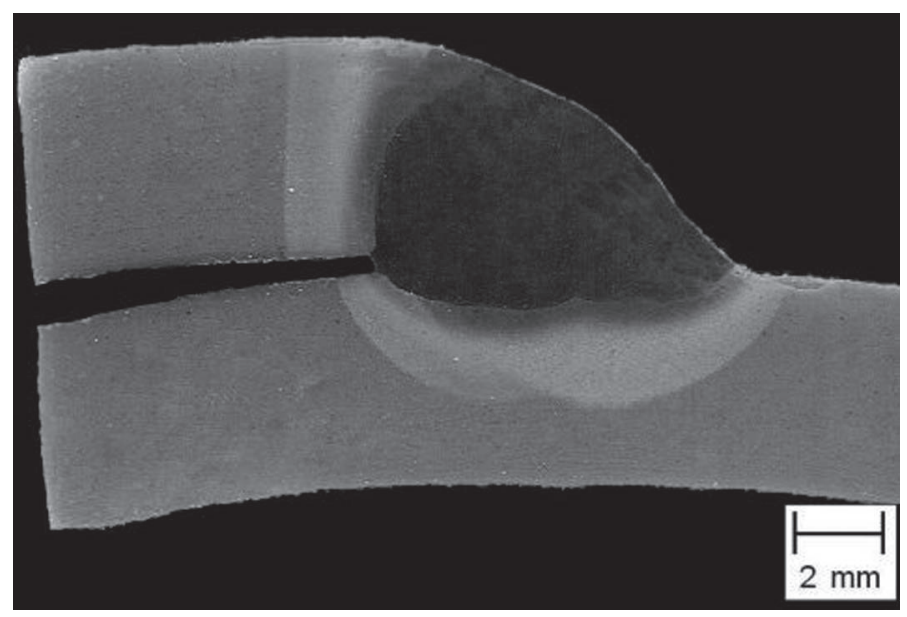

$\mathrm{C} 2$

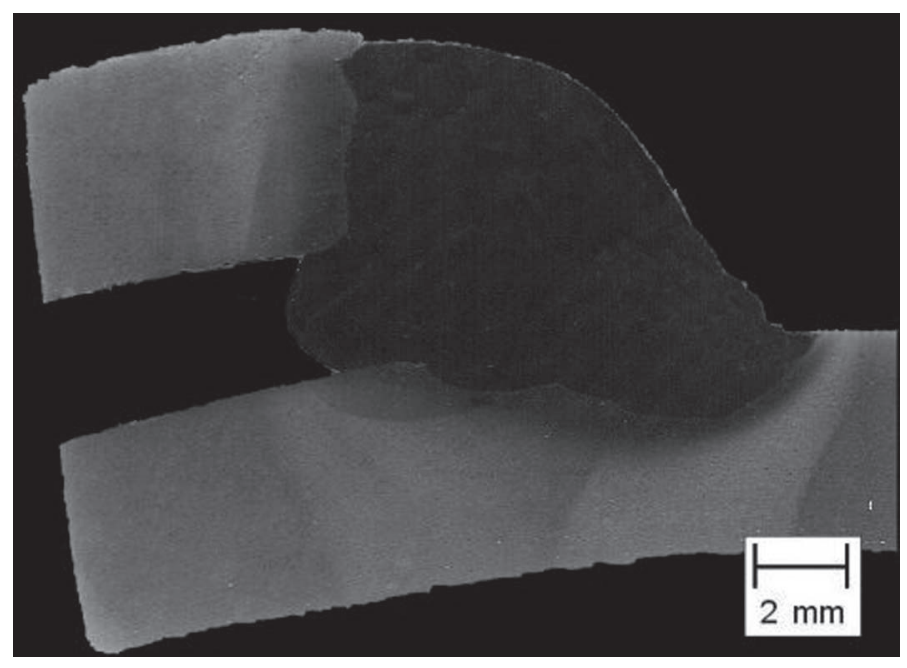

C3

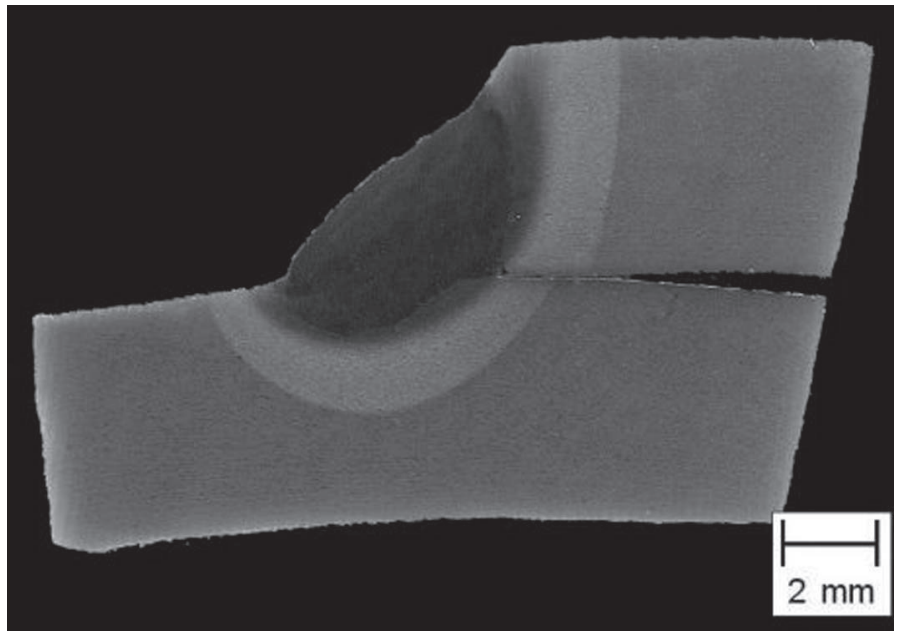

D1

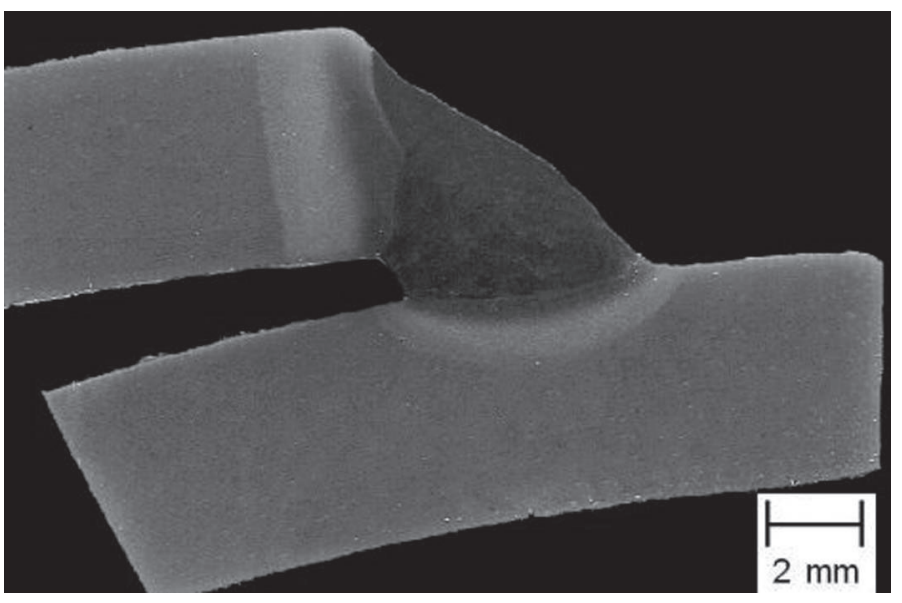

D2

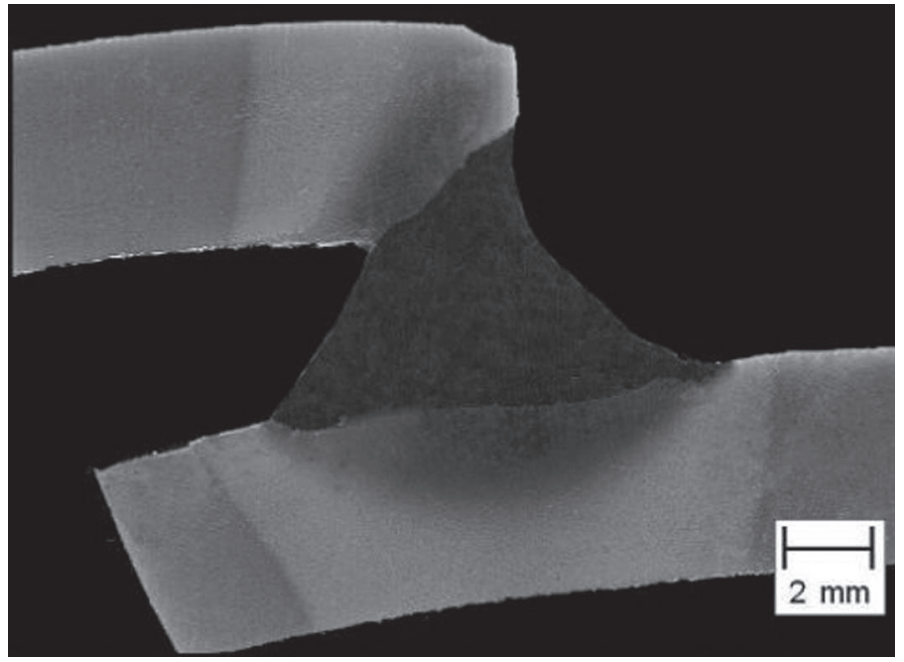

D3

Figura 7. Macrografia da solda com folga entre calha e tubo (metal de base ASTM A 335 Grau P5 e metal de solda E 8018 - B8). 


\section{Soldagem em Operação de Dutos de Alta Resistência e Baixa Espessura com Ênfase nas Trincas a Frio}

Mesmo com o uso de materiais de alto carbono equivalente na soldagem (metal de base e de adição respectivamente com 1,31 e 2,1), que em decorrência da alta dureza e da temperabilidade do aço, condições mais favoráveis para o surgimento da trinca, não foi constatada a presença da mesma.

De acordo com a literatura [2] as folgas existentes entre a calha e o tubo mostram-se propícias para o surgimento de trincas a frio, uma vez que são condições que contribuem para o aumento da tensão residual.

O escopo da execução do experimento em análise, na pesquisa da soldagem de dutos em operação pela técnica da dupla calha, foi o de possibilitar o aparecimento de uma folga proveniente da ovalização do tubo.

Os resultados mostraram, na soldagem de uma junta com folga de até $5,0 \mathrm{~mm}$ entre a calha e o tubo, a ausência de trinca nas condições de ensaio. Esta constatação contradiz a literatura sobre o surgimento de trincas a frio induzidas por hidrogênio.

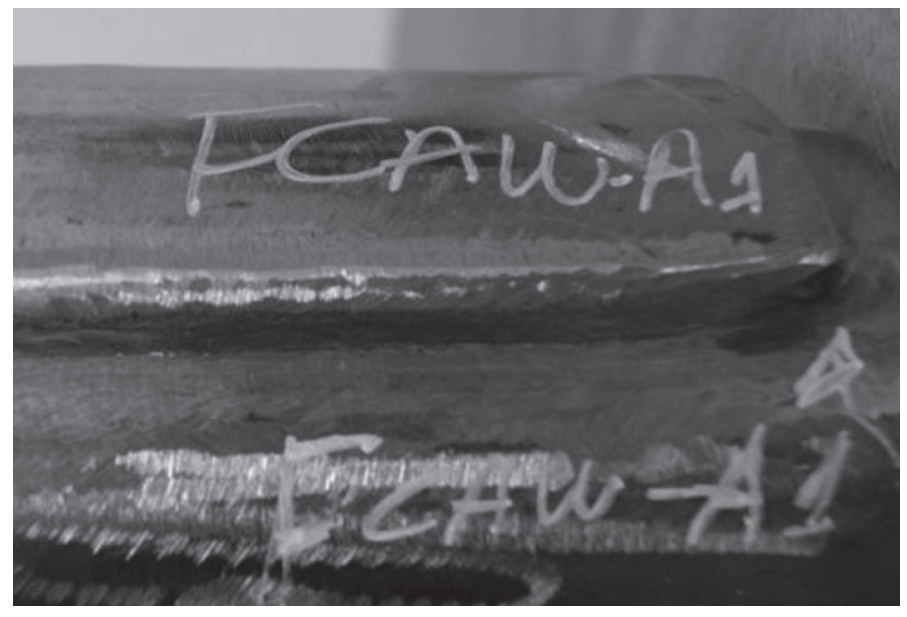

Junta A

\subsection{Efeito da restrição imposta à junta soldada.}

Com a finalidade de avaliar a ocorrência de trinca em condições mais próximas do real, para a soldagem de reparo em dutos operando com fluido interno e pressão com a técnica da dupla calha, foi executada a soldagem de acordo com os processos e parâmetros descritos no item experimento " $R$ ", com a restrição imposta à junta.

As figuras 8 e 9 mostram os filetes de solda executados com os processos GMAW em corrente pulsada com a tocha empurrando a poça de fusão e FCAW-S com transferência goticular com a tocha reta, respectivamente. Visualmente, não se observou a presença de trincas. Após esta análise, foram executados ensaios não destrutivos por líquidos penetrantes nas juntas de filete da calha com o tubo. Neste ensaio também não se detectou a presença da trincas.

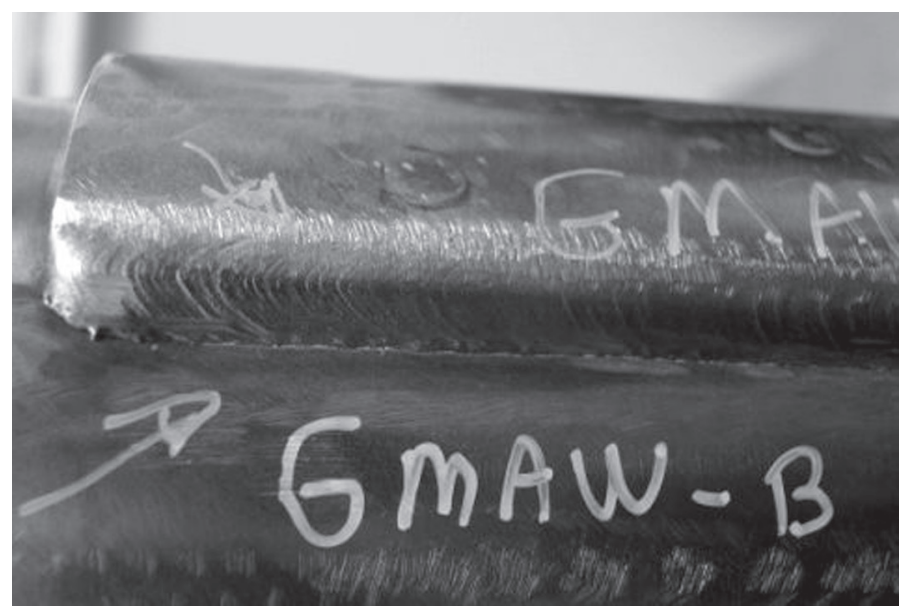

Junta B

Figura 8. Soldas de filete com o processo GMAW-P para avaliação da trinca na soldagem do tubo/calha com restrição.

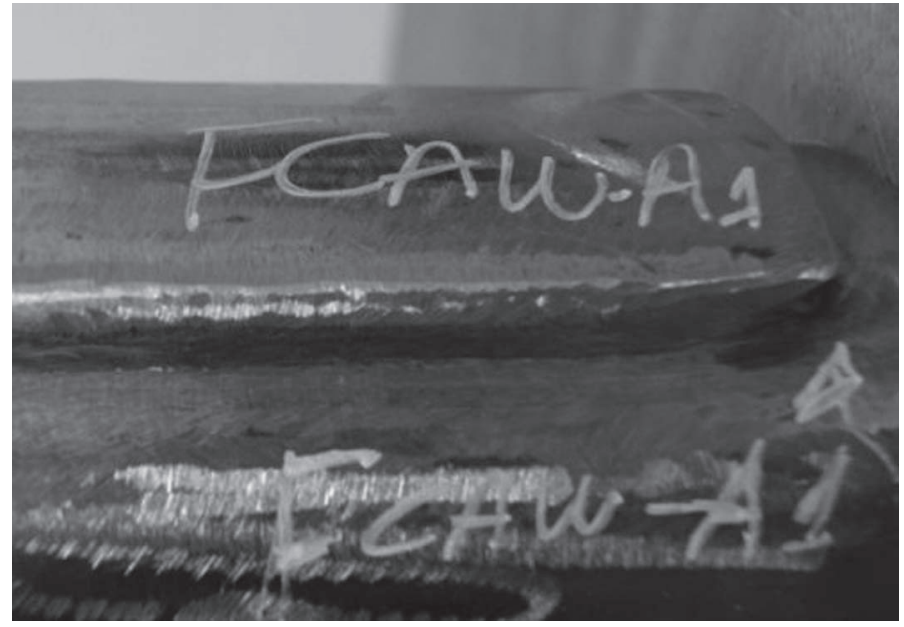

Junta A1

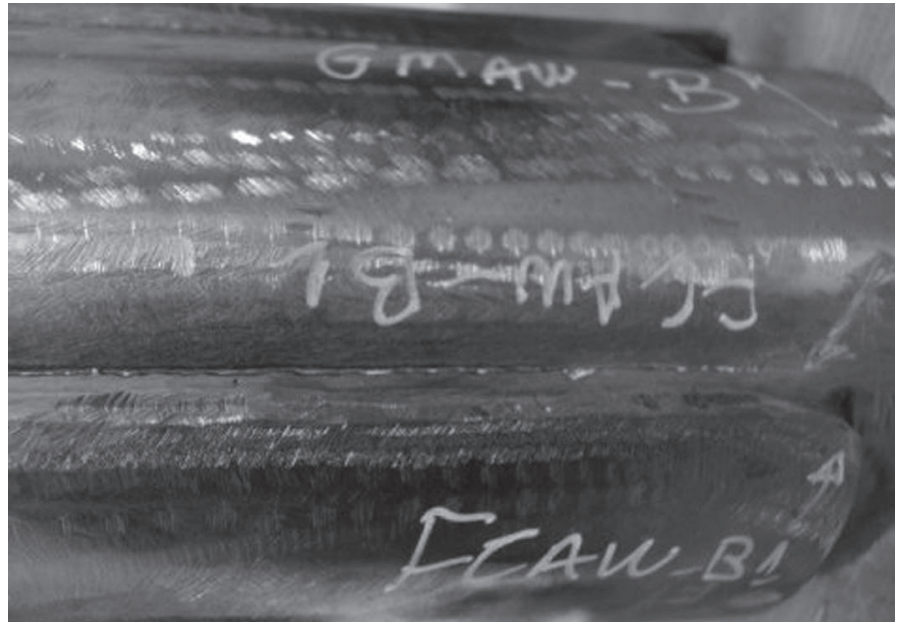

Junta B1

Figura 9. Solda de filete com o processo FCAW-S para avaliação da trinca na soldagem do tubo/calha com restrição. 
A figura 10 mostra as metalografias de uma amostra de cada junta soldada (A, B, A1 e B1). Como nos outros ensaios anteriores, neste igualmente não foi observada a presença de trincas.

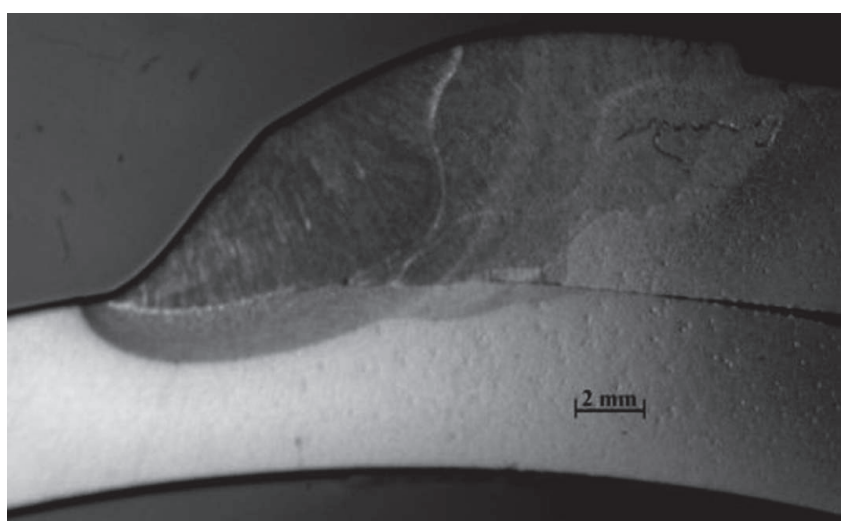

GMAW-P (junta A)

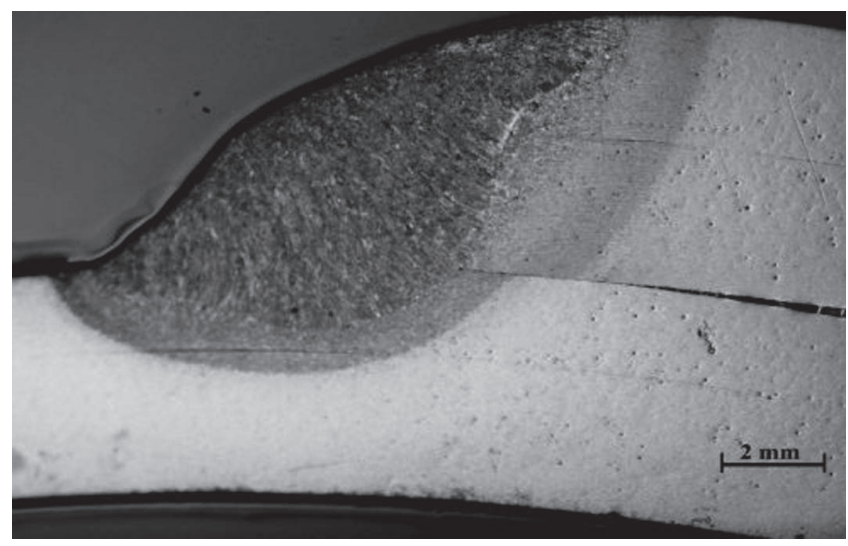

FCAW-S (junta A1)

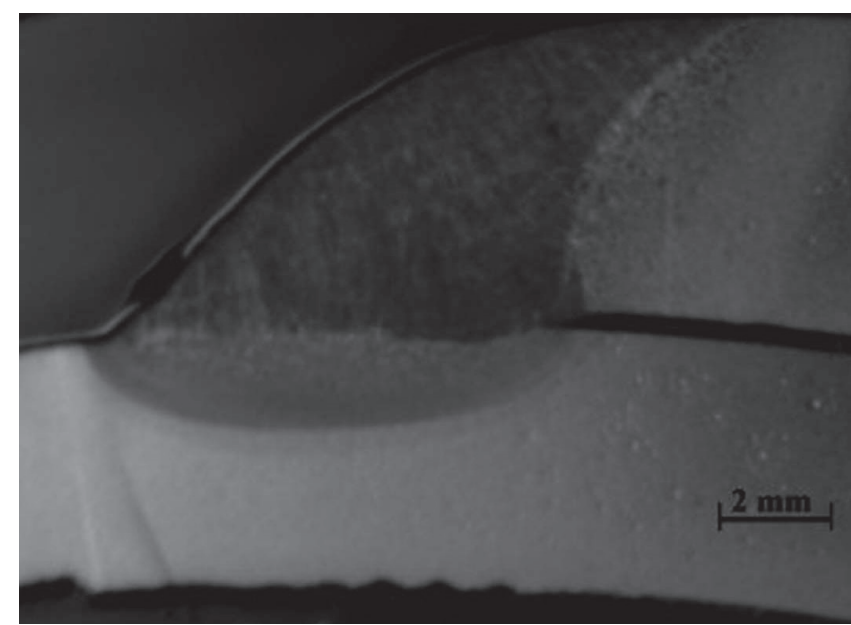

GMAW-P (junta B)

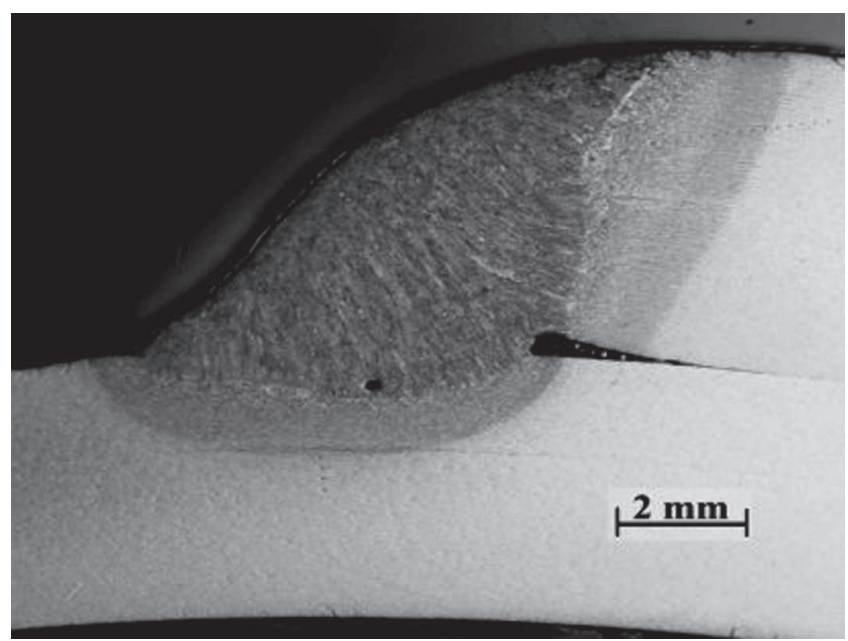

FCAW-S (junta B1)

Figura 10. Macrografias da solda com restrição entre calha e tubo

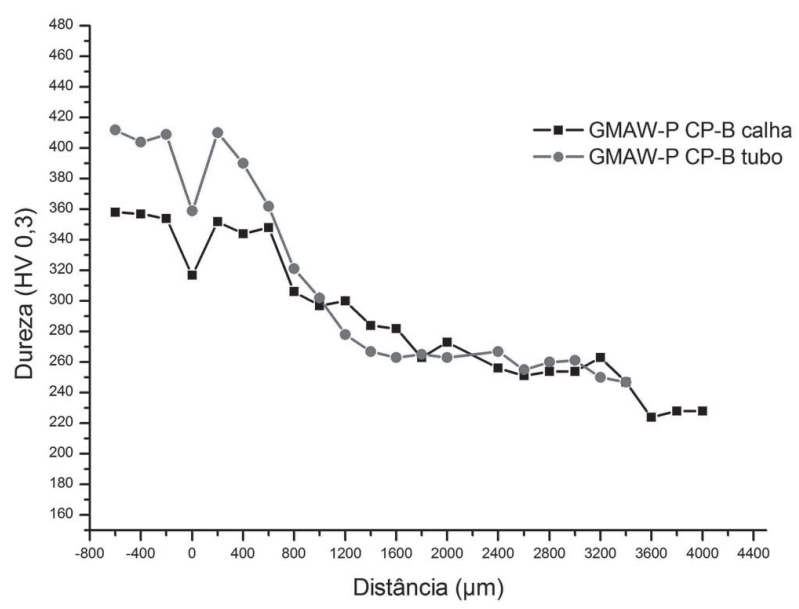

Gráfico A

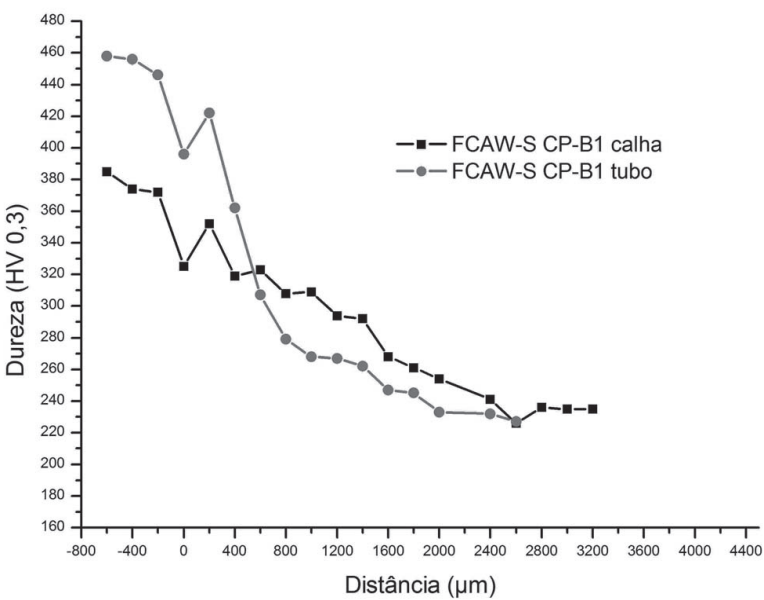

Gráfico B

Figura 11. Comparação do perfil de dureza entre tubos e calhas nos processos GMAW-P (CP-B) e FCAW-S (CP-B1). 


\section{Soldagem em Operação de Dutos de Alta Resistência e Baixa Espessura com Ênfase nas Trincas a Frio}

Entre o tubo e a calha há uma tendência de maior dureza (60 HV 0,3) para o tubo na zona fundida e início da ZAC, como pode ser visto na figura 11 (gráficos A e B).

$\mathrm{O}$ aumento da dureza nestas regiões deve ocorrer provavelmente em decorrência de haver um contato direto do tubo com a água, tendo como consequênçia uma maior taxa de resfriamento na região de contato. Mesmo com essa condição desfavorável (maior dureza) não se observou a presença da trinca.

Os ensaios de dureza (Figura 5.12) mostram que a dureza na zona fundida com o processo FCAW-S foi discretamente maior do que no processo GMAW-P, em torno de $50 \mathrm{HV}-0,3$.

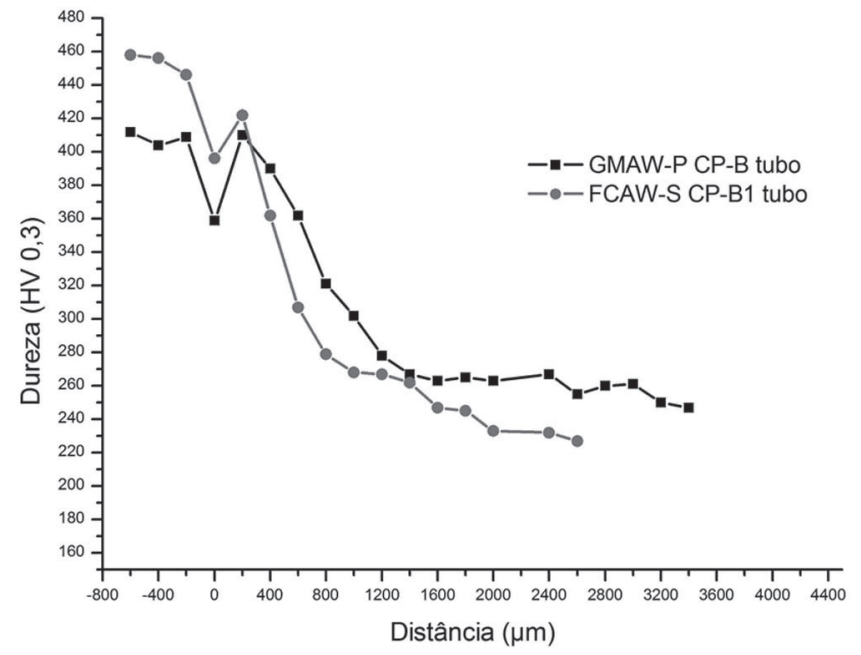

Figura 5.12 - Comparação do perfil de dureza entre tubos nos processos GMAW-P (CP-B) e FCAW-S (CP-B1).

Mesmo com maior dureza encontrada na zona fundida e início da ZAC, acima de $320 \mathrm{HV}$ 0,3 tanto para o tubo como para a calha em ambos os processos de soldagem. Mesmo com a dureza superior ao prescrito por norma, não se observou a presença da trinca a frio induzida pelo hidrogênio. A British Institution [5] determina como limite máximo de dureza de 320 Vickers.

Finalizando este trabalho de pesquisa, constata-se que não ocorreu surgimento de trincas a frio induzida pelo hidrogênio, apesar das condições favoráveis para a ocorrência da mesma como, alto carbono equivalente, alta restrição da junta e a grande folga entre a calha e o tubo, deve-se ao fato de utilizar processos de soldagem e consumíeis com baixíssimos teores de hidrogênio na solda $(\leq 5 \mathrm{ml} / 100 \mathrm{~g})$.

\section{Conclusões}

A partir da análise da literatura e dos resultados apresentados nessa pesquisa sobre a ocorrência de trincas a frio na soldagem em operação pode-se concluir:

\subsection{Quanto a função da folga entre a calha e o tubo e do alto carbono equivalente.}

- Os procedimentos de soldagem empregados, mesmo para metal base como metal de adição com alto carbono equivalente, proporcionando microestrutura martensítica e com alta dureza, não conduziram ao trincamento a frio;

- A folga maior entre a calha e o tubo $(5,0 \mathrm{~mm})$ do mesmo modo não conduziram a nenhum trincamento.

\subsection{Avaliação da ocorrência da trinca durante a soldagem em função da restrição imposta à junta soldada.}

- Mesmo condições mais próximas do real, para a soldagem de reparo em dutos operando com fluido interno e pressão com a técnica da dupla calha, com a restrição imposta à junta, não conduzem ao trincamento a frio.

- A dureza na zona fundida com o processo FCAW-S foi discretamente maior em relação ao processo GMAW-P;

- A dureza entre o tubo e a calha, dentre os processos de soldagem estudados, apresentou valores maiores para o tubo na zona fundida e no início da ZAC;

- Mesmo com uma dureza superior ao prescrito por norma na Zona Fundida e ZAC, não se observou a presença da trincas.

Admite-se que a não ocorrência da trinca a frio induzida pelo hidrogênio deve-se a utilização de processos de soldagem e de consumíveis com muito baixo teor de hidrogênio na solda.

\section{Agradecimentos}

Os autores gostariam de agradecer: Irmãos Passaúra S/A pelo fornecimento do eletrodo AWS E 8018 - B8, Hobart Brothers através da Alumaq pelo fornecimento do eletrodo E 71T-11 e Apolo Tubulares S/A pelo fornecimento do tubo API 5L X70. Em especial a UTFPR - Curitiba e a UFSC pela possibilidade de realização deste trabalho.

\section{Referências Bibliográficas}

[1] STEVENSON, M. E. et. al. Metallurgical failure Analysis of Cold Craking in a Structural Steel Weldment: Revisiting a Classic failure Mechanism. ASM International. Practical Failure Analysis, Volume 2, August 2002. P 55-60.

[2] BRUCE, W. A. ET AL. Repair of Pipelines by Direct Deposition of Weld Metal., EWI Project J7200 and J7283, June 8, 1993.

[3] PAES, Marcelo T.P. et al. Procedimentos para soldagem de dutos e tubulações industriais em operação. Relatório Técnico Final, Rio de Janeiro/RJ, 2000. 42 paginas.

[4] JIN, H. C., Research on Microstructure and Property of HAZ of $20^{\#}$ Pipeline Steel In-service Welding. China University of Petroleum, Volume 30, April 2006. P 81 - 84.

[5] BS - 5135. Process of Arc Welding C and C-Mn Steel. British Standards Institution, 1984. 